\title{
O gênero Ceratolejeunea Jack \& Steph. (Lejeuneaceae, Marchantiophyta) no Estado da Bahia, Brasil
}

\author{
Cid José Passos Bastos ${ }^{1,3}$ e Olga Yano ${ }^{2}$
}

Recebido: 14.06.2007; aceito: 20.03.2008

\begin{abstract}
The genus Ceratolejeunea Jack \& Steph. (Lejeuneaceae, Marchantiophyta) in the State of Bahia, Brazil). In this paper nine species of the genus Ceratolejeunea Jack \& Steph. are reported to Bahia, Brazil, and five of them are recorded by the first time for the State. Data on habitat, substrates, and geographic distribution are given and discussed; the morphological characters important to the circumscriptions of the species, are commented. A key to the species is also provided.
\end{abstract}

Key words: Floristic, Hepatics, Marchantiophyta, Porellales

RESUMO - (O gênero Ceratolejeunea Jack \& Steph. (Lejeuneaceae, Marchantiophyta) no Estado da Bahia, Brasil). Neste trabalho são referidas nove espécies pertencentes ao gênero Ceratolejeunea Jack \& Steph. ocorrentes no Estado da Bahia, sendo que cinco constituem primeira referência para o Estado. Dados sobre o ambiente, substrato e distribuição geográfica são apresentados e discutidos, e comentados os caracteres morfológicos importantes para a delimitação das espécies. Chave para identificação das espécies ocorrentes na Bahia também é apresentada.

Palavras-chave: Florística, Hepáticas, Marchantiophyta, Porellales

\section{Introdução}

Ceratolejeunea Jack \& Steph. é um gênero pantropical definido por claros caracteres morfológicos relacionados aos ocelos e à morfologia do perianto. As espécies neotropicais foram revisadas por Dauphin (2003), mas no Brasil o gênero necessita ser mais bem inventariado.

No estudo das espécies neotropicais, Dauphin (2003) reconheceu 23 espécies em dois subgêneros: Ceratolejeunea, com quatro espécies, caracterizado por apresentar anfigastros inteiros e perianto com cornos bulbosos, e o subgênero Caduciloba R.M. Schust., com 19 espécies e caracterizado por apresentar anfigastros bífidos e perianto com 4-5 cornos ou com quatro quilhas bem definidas. Ceratolejeunea dussiana (Steph.) G. Dauphin, espécie comum em floresta ombrófila do sul da Bahia, foi recentemente sinonimizada a Lejeunea huctumalcensis Lindenb. \& Gottsche por Reiner-Drehwald \& Ilkiu-Borges (2007). Essa espécie diferia das outras do gênero Ceratolejeunea pela coloração verde-pálida e pelo seu perianto com projeções ramificadas. No Brasil, o gênero Ceratolejeunea está representado por 14 espécies (Dauphin 2003).

No estudo mais recente sobre as Lejeuneaceae no Estado da Bahia, nove espécies foram encontradas, sendo que cinco constituem primeira referência para a Bahia, ampliando os dados de distribuição geográfica do gênero no Brasil.

O objetivo do trabalho é conhecer as espécies de Ceratolejeunea que ocorrem no Estado da Bahia, a sua distribuição e amplitude ecológica, além de identificar os caracteres taxonomicamente importantes para a delimitação das espécies.

\section{Material e métodos}

Foram estudados espécimes depositados nos Herbários ALCB, HUEFS e CEPEC, procedentes de coletas realizadas no Estado da Bahia, a maioria no período entre 1997 e 2006. Os dados de distribuição geográfica foram obtidos de Gradstein \& Costa (2003), Dauphin (2003) e Yano (2006). Informações sobre o hábitat e os grupos briocenológicos, condicionados pelos substratos colonizados (de acordo

1. Universidade Federal da Bahia, Instituto de Biologia, Departamento de Botânica, Laboratório de Taxonomia de Briófitas. Campus de Ondina, 40170-280 Salvador, Bahia, Brasil

2. Instituto de Botânica, Seção de Briologia e Pteridologia, Caixa Postal 3005, 01061-970 São Paulo, SP, Brasil

3. Autor para correspondência: cjpbasto@ufba.br 
com Fudali 2001) foram obtidos do material examinado. Estes são aqui definidos como: corticícolo (comunidade que cresce sobre ramos, caules ou tronco vivos), epifilo (comunidade que cresce sobre folhas vivas), epixílico (comunidade que cresce sobre ramos, caule, tronco ou folha morta) e liquenícolo (sobre líquens). Na distribuição no Brasil os Estados foram listados em ordem alfabética, cujas siglas estão de acordo com o Instituto Brasileiro de Geografia e Estatística -
IBGE. O tratamento taxonômico segue Dauphin (2003). Espécies referidas pela primeira vez para a Bahia estão assinaladas com asterisco.

\section{Resultados}

No Estado da Bahia foram reconhecidas nove espécies pertencentes ao subgênero Caduciloba. Descrições e ilustrações dos táxons encontrados estão em Dauphin (2003).

Chave artificial para identificação das espécies ocorrentes no Estado da Bahia

1. Margem do anfigastro com dente lateral alongado, sinus lunado ou em forma de "U"

Ceratolejeunea minuta

1. Margem do anfigastro inteira

2 Perianto sem cornos ou estes pouco desenvolvidos

3. Anfigastros grandes, ca. 3-4 a largura do que o caulídio Ceratolejeunea confusa

3. Anfigastros pequenos a medianos, ca. 1-2 a largura do que o caulídio

4. Anfigastros orbiculares, lobos em geral coniventes; filídios com ápice geralmente curvado Ceratolejeunea guianensis

4. Anfigastros ovalados a oblongos, lobos não coniventes; filídios com ápice plano

Ceratolejeunea laetefusca

2. Perianto com cornos desenvolvidos

5. Ocelos seriados

6. Ocelos em geral em duas séries; utrículos ausentes

Ceratolejeunea fallax

6. Ocelos em uma só série; utrículos presentes, raros ou ausentes

7. Anfigastros pequenos, ca. 2 vezes a largura do caulídio; lóbulos esféricos ausentes; utrículos raros ou ausentes Ceratolejeunea ceratantha

7. Anfigastros grandes, ca. 4-5 vezes a largura do caulídio; lóbulos esféricos presentes, utrículos freqüentes

Ceratolejeunea cornuta p.p.

5. Ocelos basais

8. Filídios assimétricos, margem anterior tipicamente arqueada, em geral denteada, margem posterior reta, inteira; lóbulos esféricos ausentes; utrículos raros ou ausentes

8. Filídios ovalados, margens inteiras a denteadas; lóbulos esféricos presentes ou ausentes; utrículos presentes ou ausentes

9. Anfigastros com margem levemente denteada; ocelos tipicamente geminados; utrículos e lóbulos esféricos ausentes Ceratolejeunea cubensis

9. Anfigastros com margem inteira; ocelos basais, agrupados, não geminados; utrículos e lóbulos esféricos presentes Ceratolejeunea cornuta p.p.

*Ceratolejeunea ceratantha (Nees \& Mont.) Steph., Sp. Hepat. 5: 1140. $1913 \equiv$ Lejeunea ceratantha Nees \& Mont. in Montagne, Ann. Sci. Nat. ser. 2. Bot. 14: 335. 1840.

Material examinado: BRASIL. BAHIA: Igrapiúna, Reserva Ecológica das Plantações Michelin da Bahia, $13^{\circ} 48^{\prime} 08^{\prime \prime S}, 39^{\circ} 10^{\prime} 03^{\prime \prime} \mathrm{W}$, Fragmento Pancada Grande, 21-IV-2006, C. Bastos 4512 (ALCB).

Distribuição no Brasil: AM, MG, RJ, SP.

Hábitat e briocenose: Floresta Ombrófila de Terras Baixas. Corticícolo. 
Ceratolejeunea ceratantha é caracterizada pelos ocelos seriados, em pequeno número, em geral 1-2, ausência de utrículos e de lóbulos esféricos.

*Ceratolejeunea coarina (Gottische) Schiffn. in Engler \& Prantl, Nat. Pflanzenfam. 1(3): 125. 1893 = Lejeunea coarina Gottsche, in Gottsche, Lindenb. \& Nees, Syn. Hep.: 395. 1845.

Material examinado: BRASIL. BAHIA: São Sebastião do Passé, Lamarão do Passé, $12^{\circ} 35^{\prime} 41^{\prime}$ 'S, 38²4’00”'W, 26-XI-1998, S.B. Vilas Bôas-Bastos 260 (ALCB); Santa Cruz Cabrália, Fragmento Florestal Cara-branca, $16^{\circ} 16^{\prime} \mathrm{S}, 39^{\circ} 24^{\prime} \mathrm{W}, 9-\mathrm{III}-2001, C$. Bastos \& S.B. Vilas Bôas-Bastos 2661 (ALCB); Igrapiúna, Reserva Ecológica das Plantações Michelin da Bahia, 1348'08'S, 39¹0'03"W, Fragmento Pancada Grande, 21-IV-2006, $C$. Bastos 4480 (ALCB); idem, Fragmento Pacangê, 11-VIII-2006, C. Bastos 4651 (ALCB).

Distribuição no Brasil: AC, AM, AP, MA, PA, SE, SP.

Hábitat e briocenose: cerrado antropizado e Floresta Ombrófila de Terras Baixas. Corticícolo.

Ceratolejeunea coarina é caracterizada pelos gametófitos em geral profusamente ramificados, filídios caracteristicamente assimétricos, com a margem anterior arqueada, geralmente denteada, margem inferior reta, inteira e ápice agudo, denteado. O perianto apresenta quatro cornos bem desenvolvidos, cilíndricos, em geral eretos a pouco divergentes. Utrículos e lóbulos esféricos estão, em geral, ausentes. Os ocelos são basais, em geral numerosos e agrupados.

*Ceratolejeunea confusa R.M. Schust., Journ. Elisha Mitchell Sci. Soc. 72: 313. 1956.

Material examinado: BRASIL. BAHIA: Ilhéus, 1447'20'S, 3902'58'W, Ponta da Tulha, 7-X-1995, C. Bastos \& S.B. Vilas Bôas-Bastos 779 (ALCB).

Distribuição no Brasil: AM, PA, PE, SP.

Hábitat e briocenose: Restinga arbórea. Corticícolo.

Ceratolejeunea confusa pode ser caracterizada pelos seus anfigastros grandes, imbricados a contíguos, com margem inteira, filídios com ocelos basais, agrupados a geminados, perianto sem cornos evidentes e rostro caracteristicamente longo.

Ceratolejeunea cornuta (Lindenb.) Steph. in Engler, Pflanzenwelt Ost-Afrikas C: $65.1895 \equiv$
Jungermannia cornuta Lindenb., Nova Acta Acad. Caes. Leop.-Carol. German Nat. Cur. 14 Suppl.: 23. 1829.

Material examinado: BRASIL. BAHIA: Santa Terezinha, Serra da Jibóia, $12^{\circ} 51^{\prime} 17^{\prime \prime} \mathrm{S}, 39^{\circ} 28^{\prime} 30^{\prime \prime} \mathrm{W}$, 12-IV-2002, C. Bastos 3257 (ALCB); Eunápolis, Estação Veracruz, $16^{\circ} 22^{\prime} 47^{\prime} \mathrm{S}, 39^{\circ} 10^{\prime} 20^{\prime \prime} \mathrm{W}$, 10-VI-1999, S.B. Vilas Bôas-Bastos 641 (ALCB); Ilhéus, Campus da UESC, $14^{\circ} 37^{\prime} \mathrm{S}, 39^{\circ} 10^{\prime} \mathrm{W}$, 9-II-2001, C. Bastos \& S.B. Vilas Bôas-Bastos 2402 (ALCB); Igrapiúna, Reserva Ecológica das Plantações

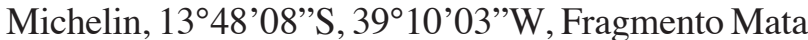
da Vila 5, 14-II-2006, C. Bastos 4158 (ALCB).

Distribuição no Brasil: AC, AM, AP, BA, CE, PA, PE, PR, RJ, RO, RR, SC, SE, SP.

Hábitat e briocenose: Floresta ombrófila de Terras Baixas e Sub-Montana e em mussununga. Corticícolo, epífilo, epixílico e liquenícolo.

Ceratolejeunea cornuta pode ser caracterizada pela presença profusa de utrículos pareados situados na base dos ramos e de lóbulos esféricos. Os ocelos são, em geral, basais, agrupados, mas podem ocorrer ocelos organizados em uma única série longitudinal, nesse caso pode ser confundida com Ceratolejeunea rubiginosa. Os anfigastros variam de medianos a grandes, orbiculares, contíguos a distantes. $\mathrm{O}$ ápice dos filídios às vezes pode ser denteado. $\mathrm{O}$ perianto apresenta quatro cornos desenvolvidos, em geral divergentes.

Ceratolejeunea cubensis (Mont.) Schiffn., in Engler \& Prantl, Nat. Pflanzenfam. 1(3): 125. $1893 \equiv$ Lejeunea cubensis Mont. in Ramón de la Sagra, Hist. Phys. Pol. Nat. Cuba: 481. 1842.

Material examinado: BRASIL. BAHIA: Igrapiúna, Reserva Ecológica das Plantações Michelin da Bahia, $13^{\circ} 48^{\prime} 08^{\prime \prime}$ S, 39¹0'03”'W, Fragmento Pancada Grande, 22-IV-2006, C. Bastos 4611 (ALCB).

Distribuição no Brasil: AC, AM, AP, BA, CE, ES, PA, PB, PE, RJ, SC, SP.

Hábitat e briocenose: Floresta Ombrófila de Terras Baixas. Epixílico.

Ceratolejeunea cubensis pode ser caracterizada pelos anfigastros grandes, com margem levemente denteada, ausência de utrículos e de lóbulos esféricos. Os ocelos são basais, em geral geminados, separados de outros pares por uma célula comum. O perianto tem cornos pouco desenvolvidos. 
*Ceratolejeunea fallax (Lehm. \& Lindenb.) Bonner, Candollea 14: 189. 1953 =Jungermannia fallax Lehm. \& Lindenb. in Lehmann, Pugillus 5: 17. 1833.

Material examinado: BRASIL. BAHIA: Igrapiúna, Reserva Ecológica das Plantações Michelin da Bahia, $13^{\circ} 48^{\prime} 08^{\prime \prime}$, 39 $9^{\circ} 10^{\prime} 03^{\prime \prime} \mathrm{W}$, Fragmento Pancada Grande, 21-IV-2006, C. Bastos 4502 (ALCB); idem, Fragmento Pacangê, 11-VIII-2006, C. Bastos 4666 p.p. (ALCB).

Distribuição no Brasil: AM, MG, PE, RJ, RO, SP.

Hábitat e briocenose: Floresta Ombrófila de Terras Baixas. Corticícolo.

Ceratolejeunea fallax pode ser caracterizada pelos ocelos organizados em duas séries longitudinais, anfigastros grandes, reniformes, ápice dos filídios denteados e ausência de utrículos e de lóbulos esféricos.

Ceratolejeunea guianensis (Nees \& Mont.) Steph., Sp. Hepat. 5: 416. 1913 =Lejeunea guianensis Nees \& Mont., Ann. Sci. Nat., Bot. ser. 2, 14: 335. 1840.

Material examinado: BRASIL. BAHIA: Jussari, 15¹1'29"S, 39²9'43'"W, Serra do Teimoso, $600 \mathrm{~m}$ alt., 20-XII-1998, M.T.S. Stradmann s.n. (ALCB).

Distribuição no Brasil: AM, BA, PA, PE.

Hábitat e briocenose: Floresta Ombrófila Submontana. Corticícolo.

Ceratolejeunea guianensis apresenta os anfigastros pequenos, orbiculares a suborbiculares, os filídios dos ramos caracteristicamente com o ápice curvado.

Ceratolejeunea laetefusca (Aust.) R.M. Schust., Journ. Elisha Mitchell Soc. 72: 306. 1956 三 Lejeunea late-fusca Aust., Bot. Gaz. 1: 36. 1876.

Material examinado: BRASIL. BAHIA: Itabuna, 144ㄱ'08"S, 39¹6'49"W, CEPLAC, 24-I-1980, D.M. Vital 8689 (SP); Ilhéus, Mata da Esperança, 1446'55"S, 3904'09”'W, 2-II-1995, L.L. Oliveira 57 (CEPEC); Eunápolis, Estação Veracruz, 16²2'47”S, 39¹0'20"W, 12-VI-1999, S.B. Vilas Bôas-Bastos \& C. Bastos 1179 (ALCB); Itacaré, 14²16'39”S, $38^{\circ} 59^{\prime} 48^{\prime \prime} \mathrm{W}$, Engenhoca, ca. $12 \mathrm{~km}$ ao sul de Itacaré, 8-II-2001, C. Bastos \& S.B. Vilas Bôas-Bastos 2365 9ALCB); Santa Cruz Cabrália, Fragmento Carabranca, $16^{\circ} 16^{\prime} \mathrm{S}, 39^{\circ} 02^{\prime} \mathrm{S}, 9-\mathrm{III}-2001$, C. Bastos \& S.B. Vilas Bôas-Bastos 2707 (ALCB); Miguel Calmon,
Parque Estadual das Sete Passagens, 11³9'19”S, 4053'55"W, Trilha do Vale do Jajai, 600-1.000 $\mathrm{m}$ alt., 21-IV-2003, C. Bastos \& S.B. Vilas BôasBastos 3381(ALCB); Igrapiúna, Reserva Ecológica das Plantações Michelin da Bahia, $13^{\circ} 48^{\prime} 08^{\prime \prime} S$, $39^{\circ} 10^{\prime} 03$ 'W, Fragmento Mata da Vila 5, Trilha do Guigó, 14-II-2006, C. Bastos 4114 (ALCB); idem, Trilha da Torre, 16-II-2006, C. Bastos 4379 (ALCB); idem, Fragmento Pacangê, 11-VIII-2006, C. Bastos 4631 (ALCB).

Distribuição no Brasil: AC, AM, BA, ES, GO, MG, PA, PE, RJ, RR, SP.

Hábitat e briocenose: Floresta Ombrófila de Terras Baixas e Floresta Estacional Montana. Corticícolo, epífilo e epixílico.

Ceratolejeunea laetefusca é uma espécie muito comum, que pode ser caracterizada pela ausência de utrículos e de lóbulos esféricos, anfigastros ovalados, distanciados, filídios com margem lisa, o ápice arredondado, liso, ocelos basais agrupados a geminados. Caracteristicamente apresenta caducidade dos filídios.

*Ceratolejeunea minuta G. Dauphin, Flora Neotropica, monógraph 90: 66. 2003.

Material examinado: BRASIL. BAHIA: Eunápolis, Estação Veracruz, 16²2'47”S, 39 10'20”W, 10-IX-1999, C. Bastos \& S.B. Vilas Bôas-Bastos 1985 (ALCB).

Distribuição no Brasil: AM, PA, PE.

Hábitat e briocenose: Floresta Ombrófila de Terras Baixas. Corticícolo.

Ceratolejeunea minuta tem como caráter mais marcante os anfigastros pequenos com pronunciado dente lateral, lobos filiformes e sinus lunado.

\section{Discussão}

O gênero Ceratolejeunea é definido pela presença de ocelos basais, seriados ou moniliados, raramente laminares, células com paredes avermelhadas e perianto com projeções alongadas (cornos) ou pouco pronunciadas. Ocelos laminares só ocorrem em Ceratolejeunea grandiloba Jack. \& Steph. e Ceratolejeunea malleigera (Spruce) Steph., espécies neotropicais não encontradas ainda no Brasil. São considerados aqui como ocelos basais aqueles situados na base do lobo, às vezes quase encobertos pelo lóbulo; 
ocelos seriados são aqueles que ocorrem em fileira longitudinal; ocelos laminares aqueles dispersos na lâmina do lobo, e/ou nos anfigastros ou nas brácteas ginoeciais. Os ocelos basais variam em número e tamanho, mas, em geral, são grandes em número de 3-4, podendo ser agrupados ou geminados (em pares).

As paredes celulares geralmente são avermelhadas ou pardas. Existem também espécies que não apresentam cornos bem desenvolvidos, a exemplo de Ceratolejeunea laetefusca e Ceratolejeunea confusa.

Grande parte das espécies de Ceratolejeunea neotropicais apresenta, em geral na base dos ramos, utrículos, os quais podem estar isolados ou em pares. Essas estruturas são oriundas do desenvolvimento desigual do filídio, em que ocorre pequeno crescimento do lobo e grande crescimento do lóbulo, o qual é enrolado e fortemente inflado formando verdadeiras bolsas que acumulam água. Lóbulos esféricos, outra também adaptação para armazenamento de água, presentes em algumas espécies, são lóbulos pequenos e fortemente enrolados e inflados (Dauphin 2003).

Ceratolejeunea tem sido coletado em florestas ombrófilas de terras baixas, mussununga, floresta estacional e cerrado, no Estado da Bahia. As áreas de cerrado em que foram coletadas algumas espécies, representam disjunções dos cerrados que recobrem grande parte do Brasil Central, e que na Bahia também podem ser encontrados no Litoral Norte e Recôncavo Baiano. Essas áreas de cerrado, no entanto, encontramse antropizadas, pois são locais com sítios e pequenas fazendas. Mussununga é um tipo de vegetação com fisionomia de restinga arbórea, com solos arenosos, e constitui um enclave na floresta ombrófila de terras baixas no sul da Bahia.

As espécies encontradas no Estado da Bahia estão representadas nas seguintes Regiões Fitogeográficas do Neotrópico (fide Gradstein et al. 2001, Gradstein \& Costa 2003): México e Sul dos Estados Unidos (Ceratolejeunea cornuta, C. laetefusca), América Central (C. coarina, $C$. confusa, $C$. cornuta, $C$. laetefusca), Caribe (C. coarina, $C$. confusa, $C$. cornuta, $C$. laetefusca), Chocó (C. coarina, $C$. confusa, C. cornuta, C. laetefusca), Norte dos Andes (C. coarina, C. cornuta) Andes Central (C. cornuta), Amazônia (C. coarina, C. confusa, C. cornuta, C. guianensis, C. laetefusca, C. minuta), Planalto das Guianas (C. cornuta, C. guianensis), Planalto Brasileiro (C. cornuta, C. laetefusca) e Atlântica Costeira (C. coarina, C. cornuta, C. laetefusca). Pode ser observado que, exceto $C$. guianensis e $C$. minuta, as demais espécies apresentam ampla distribuição no neotrópico.

Em relação à distribuição no Brasil, quatro espécies tiveram distribuição em 1-4 Estados (Ceratolejeunea ceratantha, C. confusa, C. guianensis e $C$. minuta) e cinco foram amplamente distribuídas (ocorreram em mais de quatro Estados) (C. coarina, C. cornuta, C. cubensis, C. fallax e C. laetefusca). No Estado da Bahia, C. laetefusca foi a espécie mais amplamente distribuída, ocorrendo em localidades do extremo Sul, Litoral Sul, Litoral Norte e Chapada Diamantina. Algumas espécies, como C. confusa e C. miunuta só ocorreram no sul da Bahia.

Em relação à variabilidade de substratos colonizados, observou-se que a maioria das espécies foi corticícola (oito, $88,9 \%)$, sendo seis exclusivas $(66,7 \%)$, enquanto que apenas três foram epixílicas $(33,3 \%)$, com uma exclusiva, duas foram epífilas $(22,2 \%)$, nenhuma exclusiva, e uma liquenícola, não exclusiva. Assim, o substrato preferencial foi tronco de árvore viva, seguido por tronco de árvore morta, sendo os outros ocasionais. Ceratolejeunea cornuta mostrou ser poli-substrato, integrando três grupos briocenológicos, corticícolo, epixílico e liquenícolo, e $C$. laetefusca dois grupos (corticícolo e epixílico). O que se nota a partir dessas observações é que ambas as espécies, a que apresentou maior distribuição no Brasil (C. cornuta), quanto a que apresentou maior distribuição na Bahia (C. laetefusca) foram as que integraram mais de um grupo briocenológico. Também foram as espécies que ocorreram em mais de um ecossistema.

Pode-se depreender desse estudo que o gênero Ceratolejeunea é bem representado na Bahia, visto que das 14 espécies aceitas para o Brasil, nove ocorreram no estado, o que representa $64,3 \%$ das espécies que ocorrem no Brasil e 39,2\% das espécies neotropicais. As espécies que ocorreram na Bahia, embora tenham ampla distribuição no Neotrópico e no Brasil, têm estreito espectro ecológico em relação aos substratos colonizados, a maioria delas ocorrendo em Floresta Ombrófila de Terras Baixas.

\section{Agradecimentos}

Os autores são gratos aos Curadores dos Herbários pelo empréstimo de material coletado na Bahia e às seguintes Instituições: Diretoria da Veracel Celulose pela autorização e apoio logístico e de pessoal para a realização de coleta na Estação Veracruz; Plantações Michelin da Bahia LTDA pela autorização e apoio logístico e de pessoal para 
a realização de coletas na Reserva Ecológica da Michelin; Coordenação de Aperfeiçoamento de Pessoal de Nível Superior (CAPES) pela concessão da Bolsa ao primeiro autor. Este trabalho é parte da tese de Doutorado do primeiro autor.

\section{Literatura citada}

Dauphin, G. 2003. Ceratolejeunea. Flora Neotropica, Monograph 90: 1-86.

Gradstein, S.R. \& Costa, D.P. 2003. The Hepaticae and Anthocerotae of Brazil. Memoirs of the New York Botanical Garden 87: 1-318.
Gradstein, S.R., Churchill, S.P. \& Salazar-Allen, W. 2001. Guide to the Bryophytes of Tropical America. Memoirs of the New York Botanical Garden 86: 1-577.

Fudali, E. 2001. The ecological structure of the bryoflora of wroclaw's parks and cemeteries in relation to their localization and origin. Acta Societatis Botanicorum Poloniae 70: 229-235.

Reiner-Drehwald, M.E. \& Ilkiu-Borges, A.L. 2007. Lejeunea huctumalcensis, a widely distributed Lejeuneaceae from Neotropics, and its relation to Ceratolejeunea. The Bryologist 110: 465-470.

Yano, O. 2006. Novas adições ao catálogo de Briófitas Brasileiras. Boletim do Instituto de Botânica 17: 1-142. 